\title{
Global agricultural green and blue water consumptive uses in the context of water scarcity and climate change
}

\author{
H. Yang ${ }^{\mathrm{a}}$, J.G. Liu ${ }^{\mathrm{b}}$ and C. Folberth ${ }^{\mathrm{a}}$ \\ ${ }^{\text {a }}$ Swiss Federal Institute of Aquatic Science and Technology (Eawag), P.O. Box 611, Ueberlandstrasse133, \\ CH-8600 Duebendorf, Switzerland. \\ Email: hong.yang@eawag.ch \\ ${ }^{\mathrm{b}}$ School of Nature Conservation, Beijing Forestry University, Beijing, China
}

\begin{abstract}
Agriculture, including rainfed and irrigated systems, is the single largest water user amongst all the economic sectors. There is an intrinsic linkage between water availability, food production and food security. This study takes a green and blue water perspective to model the water-food relations at the global level and on a high spatial resolution with a focus on Sub-Saharan Africa (SSA). The major issues investigated include: 1) green and blue water consumptive uses in crop production, particularly staple food crops at the global level; 2) possible impact of soil nutrient improvement and climate change on crop water uses and water productivity in SSA.
\end{abstract}

A GIS-based EPIC model (GEPIC) is applied for the investigation for 26 major crops. GEPIC is a biophysical model that simulates plant growth and yield as a function of climate, soil, and crop management using a set of experimentally derived algorithms. The model estimates crop development on a daily timestep. Potential plant growth and yield are calculated first and subsequently multiplied by stress factors to obtain actual increases in biomass and yield. Besides plant development, nutrient cycling and changes on soil structure are simulated. The main functions of plant growth are light interception, conversion of energy and $\mathrm{CO}_{2}$ to biomass, and leaf area index (LAI) development. Growth is constrained by water, nutrient (N and P), temperature, salinity, and aeration stress. The 26 crops include cereals, legumes, oil crops, cotton, sugar cane and sugar beat, fruits and vegetables.

The consumptive water use (CWU) in cropland is quantified in a spatially explicit way (30 arc-minute grid cell) by taking into account both green and blue water components. The results show that the global CWU was $5938 \mathrm{~km}^{3} \mathrm{a}^{-1}$ in the crop growing periods and $7323 \mathrm{~km}^{3} \mathrm{a}^{-1}$ in the entire year in cropland around the year 2000 . Green water contributed to $84 \%$ of the global CWU in the crop growing periods and $87 \%$ of the global CWU on an annual basis. The high proportion of green water was due mainly to the dominance of rainfed agriculture, which consumed $4068 \mathrm{~km}^{3} \mathrm{a}^{-1}$ of water in the crop growing periods and $5105 \mathrm{~km}^{3} \mathrm{a}^{-1}$ of water in the entire year. In addition, in irrigated cropland, green water contributed to $50 \%$ of the total CWU in the crop growing periods, and over $60 \%$ of the annual total CWU.

The consumptive blue water use (CBWU) was $927 \mathrm{~km}^{3} \mathrm{a}^{-1}$ in cropland on a global scale based on land cover and climate data around the year 2000. In crop growing period, blue water accounts for $16 \%$ of the global CWU. High CBWU occurs in Northern and Southern India, Eastern part of China, and the Mid Central of the USA. These regions are the major agricultural production regions in the world, and they also have very high CWU. As for the blue water proportion, regions with high values are located in the northern part of China, several West Asian countries, Middle East and North Africa, the western part of the USA, and Chile. These regions mostly have arid or semi-arid climate with low precipitation, which can only meet part of the water required by crops. In order to achieve high crop yields, irrigation water has to be supplied in addition to precipitation. Largely due to the low precipitation, irrigation depth is generally very high, resulting in high blue water proportion in these regions.

SSA is currently the region with the lowest yields and the most serious problems in food insecurity. Poor water management and soil nutrient depletion have been partly the causes. Climate change is expected to worsen the situation if no action is taken. The GEPIC model is applied to investigate impact of nutrient improvement on consumptive water uses under the current and future climate conditions. The results show that the crop water productivity (and yields) will increase significantly with sufficient nutrient input. This can be achieved with little increase in consumptive water use in most of the regions (holding the land use pattern constant) as the result of the vapor shift from evaporation to transpiration in the total evapotranspiration by crops.

Keywords: green and blue water, crop yield, climate change, uncertainty 
Yang et al., Global agricultural green and blue water consumptive uses in the context of water scarcity...

\section{INTRODUCTION}

With the population growth and the related development, particularly the increasing demand for more and better food, the consumption of water has increased continuously worldwide. In many areas of the world, water scarcity has become a major threat to the sustainable development and food security (Oki and Kanae, 2006; Vörösmarty et al., 2000; Yang et al., 2007). Currently, around one third of the world population are suffering from different levels of water stress, while the number is expected to increase substantially over the next decades. The climate change is likely to worsen the situation. Globally, agricultural water use accounts for around $70 \%$ of the total "blue" water withdrawn. When "green" water is also considered, agricultural water use consists of over $90 \%$ of the total water uses. Here, blue water refers to the water in surface water bodies and groundwater; while green water is essentially the rainfall that (after infiltration in the unsaturated zone) is directly consumed by plants to produce biomass). Water scarcity is mainly manifested as insufficient water for agricultural uses, particularly for food production (Savenije, 2000).

Previous studies have made significant improvement in the assessment of blue water uses. However, green water uses have drawn less attention. Until very recently, the term agricultural water use has mainly referred to irrigation, i.e. blue water use. With increasing water scarcity and heightened environmental concerns, there has been a gradual paradigm shift from focusing on irrigation to integrated water management concerning both irrigated and rain-fed systems. Green water is almost exclusively used by the agricultural sector and other torrential ecosystems. Consumptive water use, defined as the total evapotranspiration of a crop during the crop growth period (Falkenmark and Lannerstad, 2005), is a concept that covers both the uses of blue water and green water in agriculture. An investigation into the crop water uses with blue and green water perspectives helps gains some insights into the role of the two sources of water in food production.

Sub-Saharan Africa (SSA) is a region with extremely low yields for staple food crops due partly to poor water management and nutrient exhaustion in soils. For decades, crops have been grown without replacement of the exported nutrients in many parts of the region. In the meantime, water scarce and unreliable rainfall also impede the production and even lead to total failure of crops in the event of server droughts. Climate change is expected to increase the temporal and spatial variations on rainfall, imposing negative impact on food production and food security.

The objectives of this study are two fold: 1) assessing the consumptive water use on a global scale with high spatial resolutions and specification of proportions of green and blue water components in crop production; 2) investigating the impact of soil nutrient improvement and climate change on crop water use and yield in Sub-Saharan Africa (SSA).

\section{METHODOLOGY}

\subsection{The GIS-based EPIC Model and Data}

The GIS-based EPIC model (GEPIC) (EPIC: Environmental Policy Integrated Climate) is used for the investigation. EPIC is a bio-physical model that simulates plant growth and yield as a function of climate, soil, and crop management using a set of experimentally derived algorithms (Williams et al., 1989). It has been used for more than 20 years in a wide range of agricultural studies. GEPIC is designed to simulate the spatial and temporal dynamics of the major processes of the soil-plant-atmosphere-management system (Liu et al., 2007; Liu et al., 2009).

The GEPIC model estimates crop development on a daily time-step. Potential plant growth and yield are calculated first and subsequently multiplied by stress factors to obtain actual increases in biomass and yield. Besides plant development, nutrient cycling and changes on soil structure are simulated. The main functions of plant growth are light interception, conversion of energy and $\mathrm{CO}_{2}$ to biomass, and leaf area index (LAI) development. Growth is constrained by water, nutrient ( $\mathrm{N}$ and $\mathrm{P}$ ), temperature, salinity, and aeration stress.

There is no global data available on blue water withdrawal for irrigation. We assumed sufficient irrigation water availability when investment in irrigation equipment is made. The irrigation water is applied automatically when water stress limits plant growth $>10 \%$. Rainfed and irrigated areas for each crop are simulated separately. Yields and CWU are weighted in each grid cell subsequently by the respective fractions of each landuse system for each crop. Crop rotations and intercropping are not taken into account as the available landuse datasets refer only to single crops without further information about combinations within each grid cell. Therefore, each crop has to be assumed to be planted as a monoculture. The detail of the data used in this study is provided in Liu et al., 2009 and Folberth et al., 2011. All the simulations are performed at the grid cell level on a spatial resolution of 30 -arc minutes. 
Yang et al., Global agricultural green and blue water consumptive uses in the context of water scarcity...

A validation of model estimates with reported CWP for wheat, maize and rice from field trials has shown a good agreement in most parts of the world (Liu, 2009). Deviations between simulated and measured CWP remained mainly due to differences in fertilizer application rates which are here derived from national statistics but may differ largely in field experiments for which CWP has been reported.

\subsection{Consumptive Water Use (CWU)}

Consumptive water use (CWU) refers to the total amount of water consumed by crops in terms of evapotranspiration. In each grid cell, CWU is calculated as:

$$
\begin{aligned}
& C W U=C W U_{r}+C W U_{i} \\
& C W U_{r}=\sum_{c} C W U_{r}^{c}=10 \times \sum_{c}\left(E T_{r}^{c} \times A_{r}^{c}\right) \\
& C W U_{i}=\sum_{c} C W U_{i}^{c}=10 \times \sum_{c}\left(E T_{i}^{c} \times A_{i}^{c}\right)
\end{aligned}
$$

Where $C W U$ is consumptive water use in $\mathrm{m}^{3} \mathrm{a}^{-1}$ in one grid cell, subscript $r$ and $i$ refer to rainfed and irrigated agricultural systems, respectively. The subscript $c$ represents the crop code. ET is evapotranspiration of crop $c$ under rainfed conditions $(r)$ or irrigated conditions $(i)$ in $\mathrm{mm} \mathrm{a}^{-1}$, while $A$ is area of crop $c$ under rainfed or irrigated conditions in ha. The constant 10 converts $\mathrm{mm}$ into $\mathrm{m}^{3} \mathrm{ha}^{-1}$. In this paper, we calculated $C W U$ both in crop growing periods and in the entire year in cropland. When $C W U$ in crop growing periods was calculated, ET in crop growing periods was used. The annual $C W U$ was calculated based on ET in the entire year. After harvest of crops weeds start to grow, particularly in humid regions. In addition, intercrops are increasingly used by farmers for soil conservation or nutrient trapping. In this article, we did not take weeds and intercropping into account mainly due to the lack of data.

\subsection{Calculation of Green and Consumptive Blue Water Uses}

For rainfed crops, $C W U_{r}$ is all from green water. For irrigated crops, $C W U_{i}$ is partly from green water and partly from blue water. In order to estimate the proportion of green and blue water uses in irrigated agriculture, two different soil water balances are performed for irrigated crops.

1) Soil water balance I is carried out by assuming that the soil does not receive any irrigation water. Seasonal evapotranspiration computed using this soil water balance is referred to as SET1.

2) Soil water balance II is carried out by assuming the soil receives irrigation water. Seasonal evapotranspiration computed using this soil water balance is referred to as SET2.

For a specific crop under irrigated conditions, according to FAO (2005), green water use is equal to SET1, while blue water use is equal to the difference between SET2 and SET1, or SET2-SET1 in crop growing periods. Hence, for a specific crop under irrigated conditions, the proportion of blue water in crop growing periods is calculated as:

$$
b_{i}^{c}=\frac{S E T 2^{c}-S E T 1^{c}}{S E T 2^{c}}
$$

where $\mathrm{b}$ is the blue water proportion of crop $c$ under irrigated conditions $i$.

In a grid cell, consumptive blue water use $(C B W U)$ for all crops can be estimated as:

$$
C B W U=\sum_{c}\left(b_{i}^{c} \times C W U_{i}^{c}\right)
$$

The blue water proportion $(B)$ and green water proportion $(G)$ in each grid cell are calculated as follows:

$$
\begin{aligned}
& B=\frac{C B W U}{C W U} \\
& G=1-B
\end{aligned}
$$

With Eq. (6), blue water proportion in both crop growing periods and in the entire year are calculated. It is assumed that irrigation is not applied in non-growing periods. Hence, $C B W U$ remains the same for the crop growing periods and the entire year. $C W U$ during the growing periods differs from that during the entire year, leading to different blue water proportion in the two calculations. 
Yang et al., Global agricultural green and blue water consumptive uses in the context of water scarcity...

\section{CROP BLUE AND GREEN WATER USES}

\subsection{Consumptive Water Use (CWU)}

The simulation results show that the global CWU in crop growing periods was $5938 \mathrm{~km}^{3} \mathrm{a}^{-1}$ in cropland around the year 2000 (the average of the years 1998-2002). Spatial patterns of CWU are demonstrated in Fig. 1a. The highest CWU per grid cell (e.g. $>400$ million $\mathrm{m}^{3} \mathrm{a}^{-1}$ ) was found in most part of India, eastern part of China, some countries in Southeast Asia such as Indonesia, Mid Central of the USA, part of Argentina and Brazil, and very few countries in Africa (e.g. Nigeria, Ghana, and Ivory Coast). These regions represent the most intensive agricultural production area in the world. In Europe, CWU in most grid cells is between 300 and 400 million $\mathrm{m}^{3} \mathrm{a}^{-1}$. In other parts of the world, CWU was generally lower than 100 million $\mathrm{m}^{3} \mathrm{a}^{-1}$.

Spatial pattern of annual CWU in the entire year is similar to that of CWU in the crop growing periods (Fig. 1a vs. Fig. 1b). At the global level, annual CWU was $7323 \mathrm{~km}^{3} \mathrm{a}^{-1}$ in cropland around the year 2000. This means that $81 \%$ of the annual CWU was used in the crop growing periods, while the remaining $19 \%$ occurred in the non-growing periods. At the river basin level, Mississippi, Yangtze, Ganges and Nile are the four river basins with the highest CWU both during the growing periods and for the entire year. These four river basins account for around $20 \%$ of the global CWU.

\section{a. Consumptive Water Use in Crop Growing Periods}

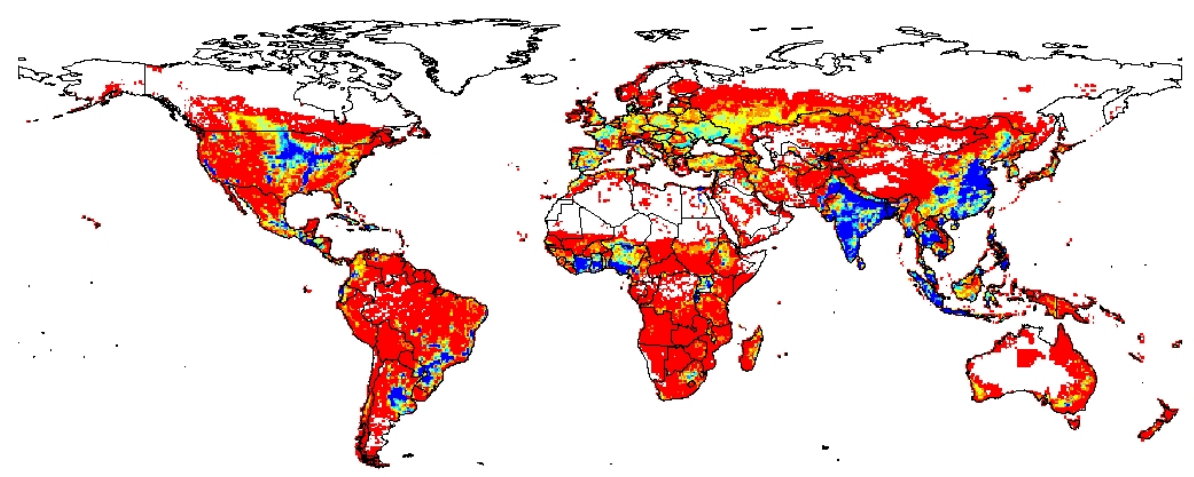

b. Annual Consumptive Water Use
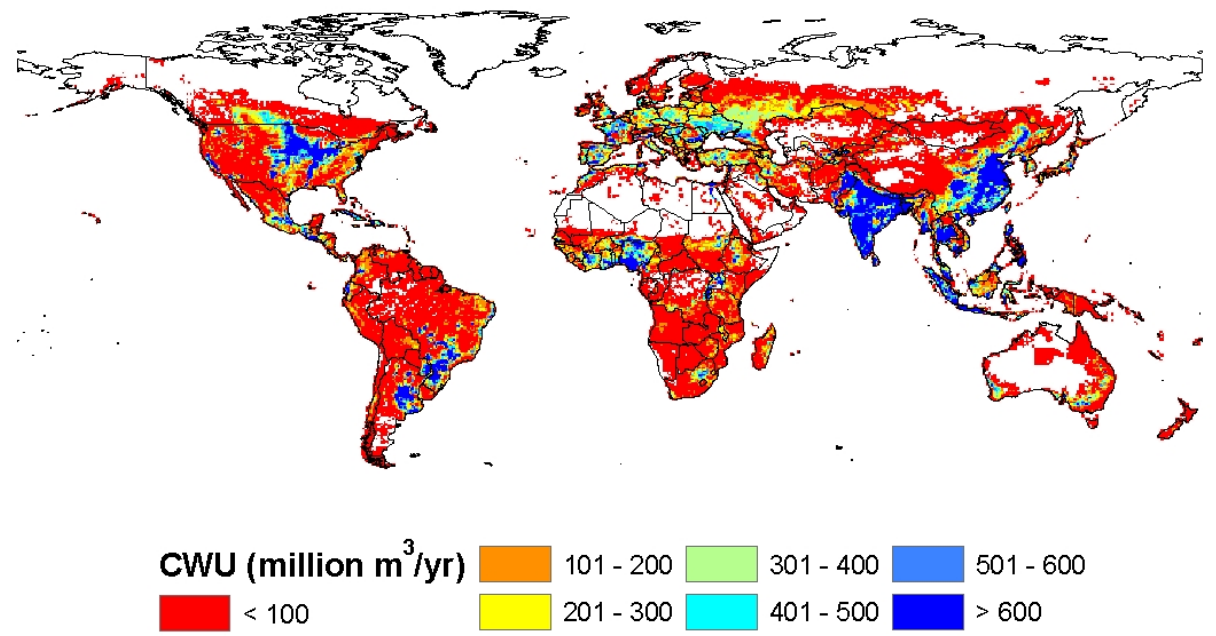

Figure 1. Spatial pattern of consumptive water use in cropland around the year 2000 (a) in crop growing periods (b) in the entire year

\subsection{Consumptive Blue and Green Water Use (CBWU)}

The consumptive blue water use (CBWU) was estimated at $927 \mathrm{~km}^{3} \mathrm{a}^{-1}$ in cropland on a global scale based on land cover and climate data around the year 2000. Hence, in crop growing period, blue water accounts for $16 \%$ of the global CWU, while green water accounts for $84 \%$. On an annual basis, the figures are $13 \%$ and $87 \%$ for blue water and green water, respectively. High CBWU occurs in Northern and Southern India, Eastern part of China, and the Mid Central of the USA (Fig. 2a). These regions are the major agricultural 
production regions in the world, and they also have very high CWU. As for the blue water proportion, regions with high values are located in the northern part of China, several West Asian countries, Middle East and North Africa, the western part of the USA, and Chile (Fig. 2b). These regions mostly have arid or semiarid climate with low precipitation. Precipitation can only meet part of the water required by crops. In order to achieve high crop yields, irrigation water has to be supplied in addition to precipitation. Largely due to the low precipitation, irrigation depth is generally very high, resulting in high blue water proportion.

It is noted that in some regions of the world, blue water use in total water use is almost negligible (Fig. 2). In most parts of the SSA region, crop production is entirely rainfed. The crop water use relies solely on green water (or soil moisture). In these regions, sufficient and reliable soil water supply is vital for the stability of crop production.
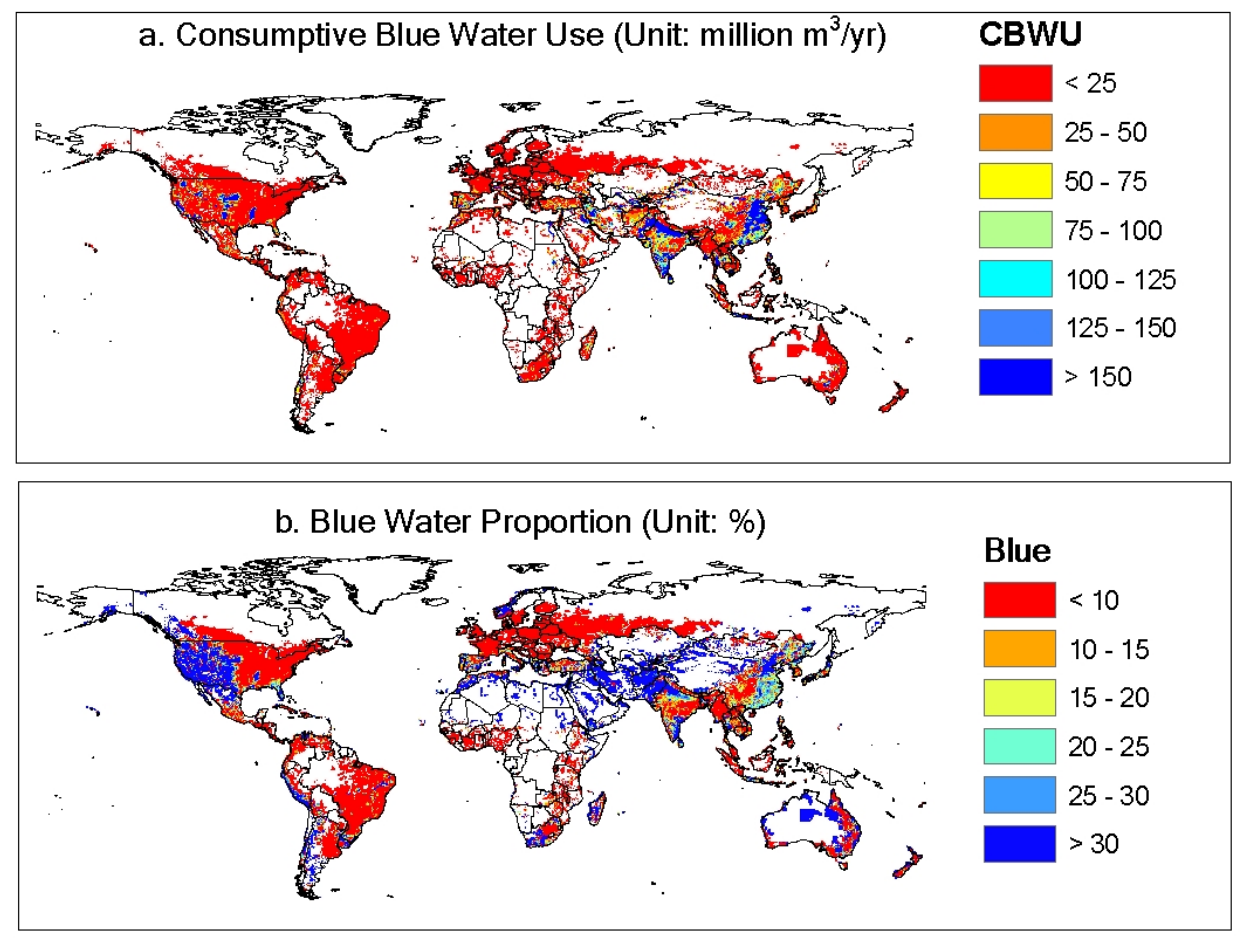

Figure 2. Spatial pattern of (a) consumptive blue water use and (b) blue water proportion in crop growing periods in cropland

\section{IMPACT OF SOIL NUTRIENT IMPROVEMENT AND CLIMATE CHANGE ON CROP WATER USE}

SSA is currently the region with the lowest yields and crop water productivity (CWP) globally. Many studies have found that poor soil water and nutrient conditions is part of the reason. Climate change is expected to worsen the situation in many areas. Improving the soil water and nutrient management is of great importance to enhance CWP and yield, and hence food security, particularly for small subsistence farmers. This section provides an analysis of the impact of improving soil nutrient supply on crop water uses and CWP in SSA under the current and future climate conditions.

Fig. 3 shows the CWP of maize in SSA under the current and future climate conditions with and without nutrient improvement. In general, the CWP is below $0.4 \mathrm{~kg} / \mathrm{m}^{3}$ with the status-quo soil nutrient condition (Fig.3a, Fig.3c). The CWP increases significantly with the sufficient supply of nutrient in soil (Fig 3b, Fig.3d), to around $1 \mathrm{~kg} / \mathrm{m}^{3}$ in most of the areas. The results indicate that in most regions the low yields are attributed to the lack of nutrients in soils. While the CWP of maize in SSA is at the bottom of global recorded CWP with current inputs, it could be in the mid to upper range with full nutrient supply. But there are water scarce regions (e.g. Horn of Africa and Kalahari), in which improving nutrient supply alone can not increase the CWP and yields substantially.

Fig. 4 shows changes in consumptive green water use between the status quo situation and with sufficient nutrient supply under the current and future climate conditions. It can be seen that an increase in CWP by sufficient nutrient supply leads to a rather small increases in the consumptive water use in most of the areas in SSA. As shown in Figs. $4 \mathrm{c}$ and $4 \mathrm{f}$, the ratio of consumptive green water uses with and without nutrient 
improvement in maize production is mostly around $100 \%$, meaning no change in total consumptive water use. The significant increases in water use, however, can be seen in western part of the tropical Africa and southern Africa.

The simulation results suggest that climate change will on average not affect maize yields in SSA dramatically both under business as usual nutrient condition (-5\%) and under sufficient nutrient supply ($7 \%$ ). But the impact can locally be up to $-50 \%$, especially in low-yielding arid regions like the southwestern African coast, other parts of southern Africa, and parts of the Sahel zone. On the other hand, increases are possible especially in eastern African countries like Kenya, Tanzania, and southern Ethiopia. These yield increases go mostly along with improvements in CWP (Figs. 3c and 3d).

a)

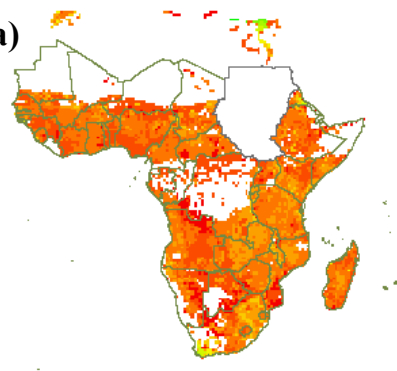

c)

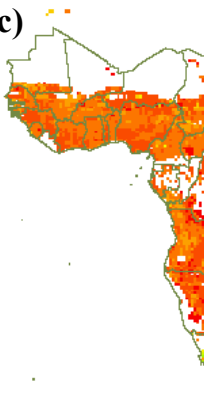

b)

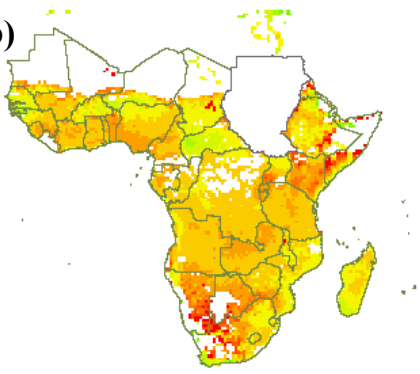

d)

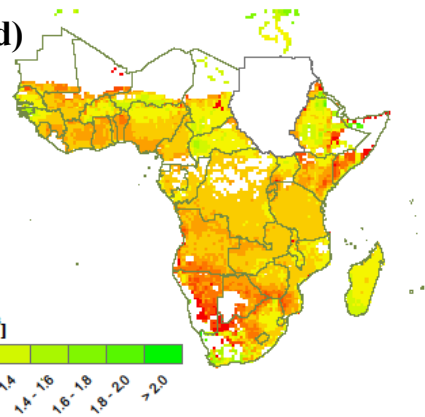

Figure 3. Crop water productivity for maize in sub-Saharan Africa. (a) Under current climate with businessas-usual, (b) under current climate with sufficient nutrient supply, (c) under future climate with business-asusual, (d) under future climate with sufficient nutrient supply.

a)

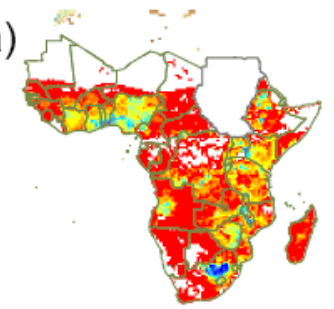

d)

b)

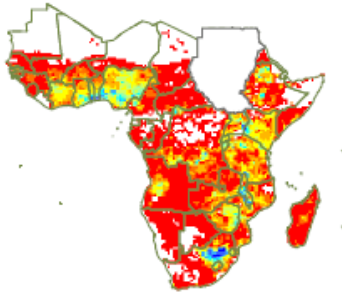

e)
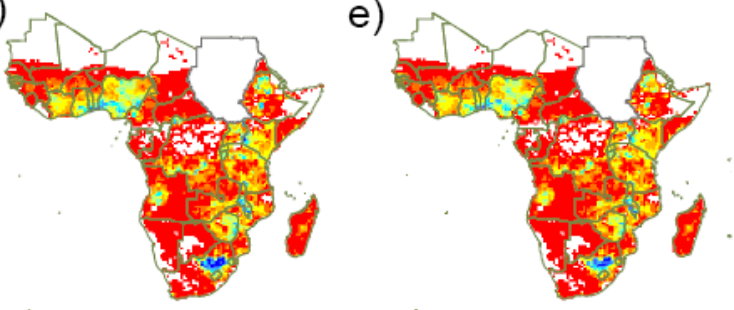

c)

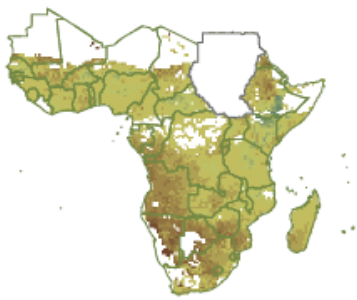

f)

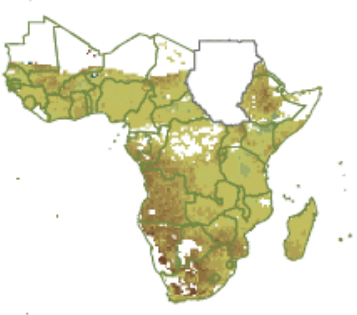

Consumptive water use $\left[10^{6} \mathrm{~m}^{3} \mathrm{yr}^{-1}\right]$

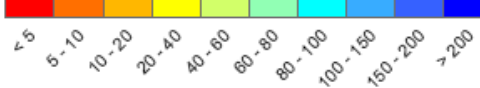

Change in CWU under climate change [\%]

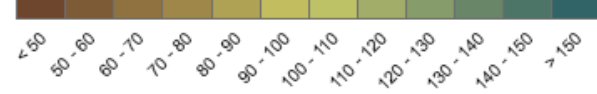

Figure 4. Consumptive water use for maize in SSA. (a) under current climate with business-as-usual, (b) under future climate with business-as-usual, (c) percentage change of (a) and (b) under climate change, (d) 
Yang et al., Global agricultural green and blue water consumptive uses in the context of water scarcity...

under current climate with sufficient nutrient supply, (e) under future climate with sufficient nutrient supply, f) percentage change of (d) and (e) under climate change. $100 \%=$ no change.

\section{CONCLUSION}

We quantified consumptive water use (CWU) in cropland in a spatially explicit way by taking into account both the green and blue water components. The results show that the global CWU was $5938 \mathrm{~km}^{3} \mathrm{a}^{-1}$ in the crop growing periods and $7323 \mathrm{~km}^{3} \mathrm{a}^{-1}$ in the entire year in cropland around the year 2000 . Green water contributed to $84 \%$ of the global CWU in the crop growing periods and $87 \%$ of the global CWU on an annual basis. The high proportion of green water was due mainly to the dominance of rainfed agriculture, which consumed $4068 \mathrm{~km}^{3} \mathrm{a}^{-1}$ of water in the crop growing periods and $5105 \mathrm{~km}^{3} \mathrm{a}^{-1}$ of water in the entire year. In addition, in irrigated cropland, green water contributed to $50 \%$ of the total CWU in the crop growing periods, and over $60 \%$ of the annual total CWU. The important role of green water in crop production gives rise to the need for a better management of this water resource. Improving green water management should be an important option to guarantee world food security in the future.

The impact of nutrient supply and climate change in the SSA region is investigated with the GEPIC model. The results suggest that improving nutrient supply in the soil will significantly increase crop yields and water productivity. The consumptive water use, however, will only increase in a much lesser extent as the result of the vapor shift from evaporation to transpiration in total evapotranspiration. A better soil nutrient management could play a crucial role in improving water use efficiency and food security in the SSA region both today and in the future. Overall, the climate change will have no significant negative impact on crop yield and water productivity in the SSA region.

\section{REFERENCES}

Alcamo, J., Henrichs, T. and Rösch, T., 2000. World water in 2025: Global modeling and scenario analysis for the world commission on water for the 21 st century. Kassel World Water Series 2. University of Kassel, Kassel, Germany.

Döll, P., Kaspar, F. and Alcamo, J., 1999. Computation of global water availability and water use at the scale of large drainage basins. Mathematische Geologie, 4: 111-118.

Falkenmark, M. and Lannerstad, M., 2005. Consumptive water use to feed humanity - curing a blind spot. Hydrology and Earth System Sciences, 9: 15-28.

Folberth, C., Gaiser, T., Abbaspour, K., Schulin, R., Yang, H., Regionalization of a large-scale crop growth model for sub-Saharan Africa - Model setup, evaluation, and estimation of crop yields. Submitted to Agriculture, Ecosystems and Environment.

Liu, J., Williams, J.R., Zehnder, A.J.B. and Yang, H., 2007b. GEPIC - modelling wheat yield and crop water productivity with high resolution on a global scale. Agricultural Systems, 94(2): 478-493.

Liu, J., 2009. A GIS-based tool for modelling large-scale crop-water relations. Environ. Modell. Softw. 24, 411-422.

Liu, J., Zehnder, A.J.B. and Yang, H., 2009. Global consumptive water use for crop production: the importance of green water and virtual water. Water resources research, 45: W05428.

Oki, T. and Kanae, S., 2006. Global hydrological cycles and world water resources. Science, 313(5790): 1068-1072.

Rockström, J., 2003. Water for food and nature in drought-prone tropics: vapor shift in rain-fed agriculture. Philosophical Transactions of the Royal Society of London B Biological Sciences, 358(1440): $1997-$ 2009.

Savenije, H.H.G., 2000. Water scarcity indicators; the deception of the numbers. Physics and Chemistry of the Earth, 25(3): 199-204.

Siebert, S. and Döll, P., 2008. The Global Crop Water Model (GCWM): Documentation and first results for irrigated crops. Frankfurt Hydrology Paper 07, Institute of Physical Geography, University of Frankfurt, Frankfurt am Main, Germany.

Vörösmarty, C.J., Green, P., Salisbury, J. and Lammers, R.B., 2000. Global Water Resources: Vulnerability from Climate Change and Population Growth. Science, 289(5477): 284-288.

Yang, H. and Jia, S., 2008. Meeting the basin closure of the yellow river in China. International Journal of Water Resources Development, 24(2): 265.

Williams JR, Jones CA, Kiniry JR, Spanel DA (1989) The EPIC crop growth model. T ASAE 32: 497-511. 